THE INTERNATIONAL

REVIEW OF RESEARCH IN

OPEN AND DISTANCE LEARNING

\title{
Contradictions in a Distance Course for a Marginalized Population at a Middle Eastern University
}

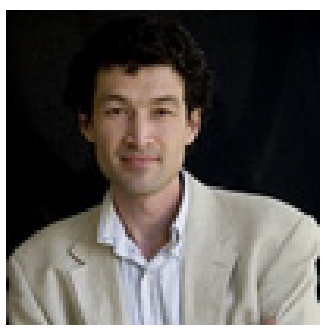

Irshat Madyarov American University of Armenia Aida Taef

\section{Abstract}

This study explores six cases of non-native English speaking students engaged in a distance English-medium course on critical thinking at a university in Iran. Framed within activity theory, the study investigated students' course-related activity systems with a particular focus on contradictions that underlie any human activity. The construct of contradictions provides a theoretical lens to understand a web of relationships among a number of elements in course-related activities situated in a cultural-historical setting beset with political controversies, technological challenges, and needs for a bilingual curriculum. The findings indicate that all student participants had multiple activity systems within the course environment. Most participants had primary, secondary, and quaternary contradictions that had positive and negative consequences on the expansion of their activity systems. Discussion also includes practical implications for the distance university under study that could potentially be applied to similar distance schools.

Keywords: Activity theory; contradictions; open; distance; English as a foreign language; Middle East 
This paper discusses a qualitative case study of a distance course offered in English to nonative English speaking college students in Iran. The researchers represent an insider perspective as faculty members. The study has grown out of their personal motive to analyze the inner workings of this distance university placed within a unique sociopolitical setting.

Subsequent to the 1979 Islamic Revolution in Iran, many non-Muslim minorities were severely marginalized. Among them were the followers of the Bahá'i Faith, who have been systematically precluded from attending tertiary educational institutions. The Bahá'í Institute for Higher Education (henceforth, Institute) was founded in 1987 to restore the birthright of Bahá'í youth to access higher education (History and overview, 2011). Bahá'í professors and instructors who were themselves dismissed from universities and colleges on the grounds of their religious beliefs volunteered to provide the Iranian Bahá'i youth with a means to acquire higher education. As a result, they joined forces to establish the Institute. At the initial stages, very few programs were offered by the institute and due to security cautions courses were generally delivered by correspondence or, where possible, in small classes held in private homes. Today, the Institute has grown to offer 32 universitylevel programs across five colleges in Sciences, Engineering, Business and Management, Humanities, and Social Sciences. The advent of new technologies has made it possible for the affiliated global faculty (AGF), which consists of many professors outside Iran, to assist the Institute in offering courses in a distance or blended mode. Many of these courses are offered in English by non-Farsi speaking faculty. This has added yet another layer of complexity; now students' English proficiency should be high enough to handle college-level courses in English. Although the Institute has been successful in providing students with needed knowledge and skills, the oppression does not seem to cease and the faculty and students have been subject to numerous arrests, periodic raids, and confiscation of school equipments.

To investigate this complex web of interrelations and understand how distance learning operates under such conditions, the researchers have chosen a qualitative method of inquiry with a case study design framed within activity theoretical perspective. The following is a discussion of activity theory that will contextualize the methodology, analysis of data, and findings.

\section{Theoretical Framework of Activity Theory}

Activity theory represents one of the valuable assets of qualitative naturalistic inquiry. Since its birth in the first part of the $20^{\text {th }}$ century, many forms of activity theory have emerged. This study adopts the activity theory framework, often referred to as the third generation of activity theory, which was developed by the Scandinavian school and spearheaded by Yrjö Engeström and his colleagues. What follows is a concise chronological description of activity theory as presented by Engeström (1987, 1999a, 1999b, 2001).

Activity theory evolved from cultural historical psychology, whose origins are rightly attributed to Lev Vygotksy, a Russian psychologist and educator. His theory is based on the ideas 
of German philosophers Kant, Hegel, Marx, and Engels (Engeström, 1987). At the heart of Vygotsky's theory is the idea that human beings perform all conscious actions towards achieving their goal by means of mediating instruments, either physical, such as a pen or hammer, or psychological, such as language (Vygotsky, 1982b). This original theoretical model is considered the first generation of activity theory (Engeström $(1987,1999 a, 1999 b$, 2001).

The second generation of activity theory came about through the efforts of Leont'ev (1975, 1981, 1989), who actually coined the term activity theory. He took individual human actions theorized by Vygotsky to the level of collective activity. By doing this, he connected his theory directly to the original sources of Vygotsky's ideas: Kant, Hegel, and Marx. Thus, activity becomes the smallest unit of analysis that contains all the elements of human collective activity, namely subject, instruments, object, division of labor, community, and rules (Figure 1).

\section{Rules}

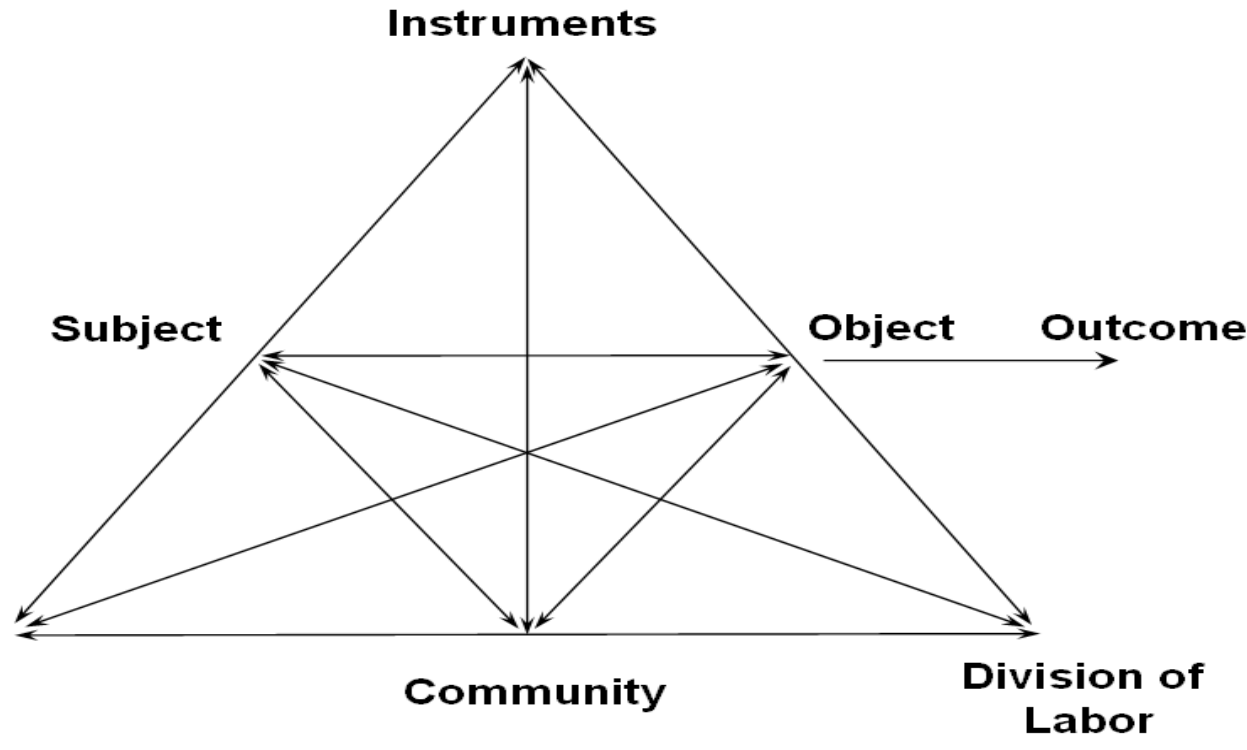

Figure 1. A model of human activity proposed by Leont'ev (cited in Engeström, 2001, p. 135).

By changing the focus in the unit of analysis, Leont'ev (1981) shifted attention from the individual to the collective. Lantolf and Thorne (2006) offer a concise summary of the three levels of activity in the form of a chart (Table 1). Starting from the bottom, each level of activity is built upon the preceding one. Action is built upon operations, and activity is built upon actions. The same set of operations can be used to accomplish different actions. Similarly, the same actions can be driven by different motives or objects. 
Table 1

Hierarchy of Activity (Adapted from Lantolf and Thorne, 2006, p. 217)

Everyday descrip- Unit of analysis Oriented toward Carried out by Time frame
tion

\begin{tabular}{|c|c|c|c|c|}
\hline $\begin{array}{l}\text { Why something } \\
\text { takes place }\end{array}$ & Activity & $\begin{array}{l}\text { Motive, transformation of } \\
\text { object }\end{array}$ & $\begin{array}{l}\text { Community and/or } \\
\text { society }\end{array}$ & $\begin{array}{l}\text { Recurrent, cyclic, } \\
\text { iterative }\end{array}$ \\
\hline What is being done & Action & Goal & Individual or group & Linear, finite \\
\hline The actual doing & Operations & Condition(s) & Individual & $\begin{array}{l}\text { Present moment, } \\
\text { process ontology }\end{array}$ \\
\hline
\end{tabular}

Engeström (2001) further adds interactivity among different activity systems, which becomes the third generation of activity theory. Figure 2 shows how two objects formed in two separate collective activity systems come together to form a new object common to two different groups of people (Engeström, 2001).

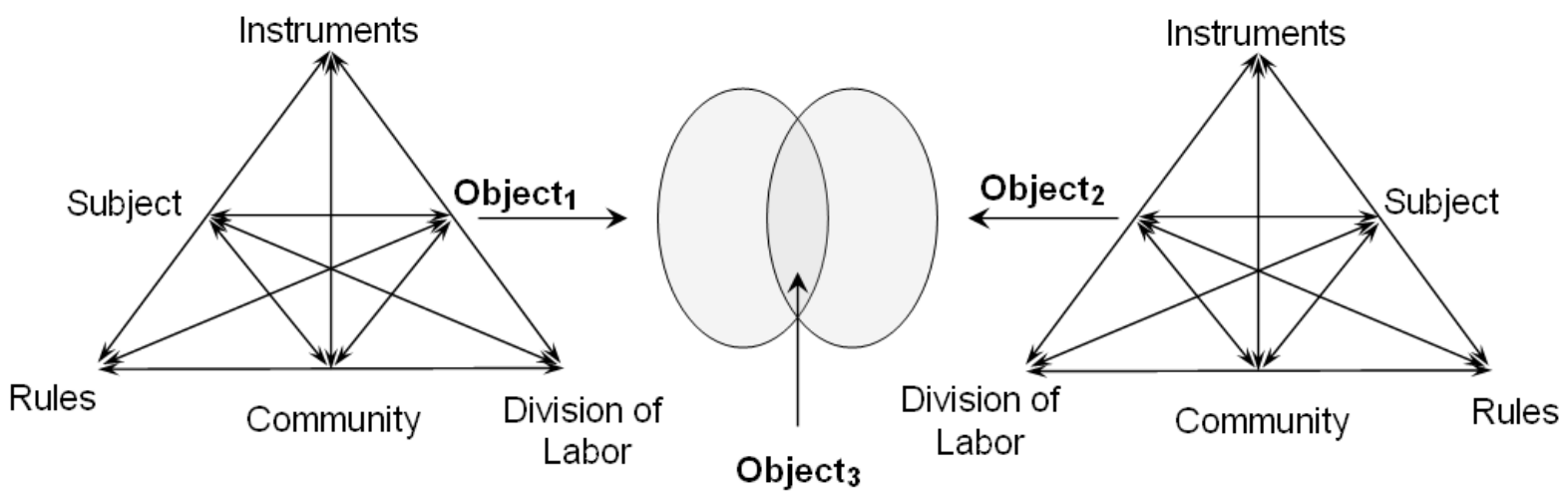

Figure 2. A model of activity theory (Engeström, 2001, p. 136).

Engeström (2001) suggests several principles of activity theory. The first of these principles is that "a collective, artifact-mediated [same as instrument-mediated], and object-oriented activity system" should be viewed in the context of other surrounding activity systems, that is the network of activity systems (Engeström, 2001, p. 136). In Figure 3, one can see these activity systems within a central activity system of a doctor's medical practice (Engeström, 1987). The second principle that Engeström (2001) suggests is the multivoicedness of activity systems, realized in participants' traditions, interests, opinions, and the diversity of instruments, rules, and histories present in any activity system. The third principle highlights the historicity of activity systems in that they always carry past history and change over time. 


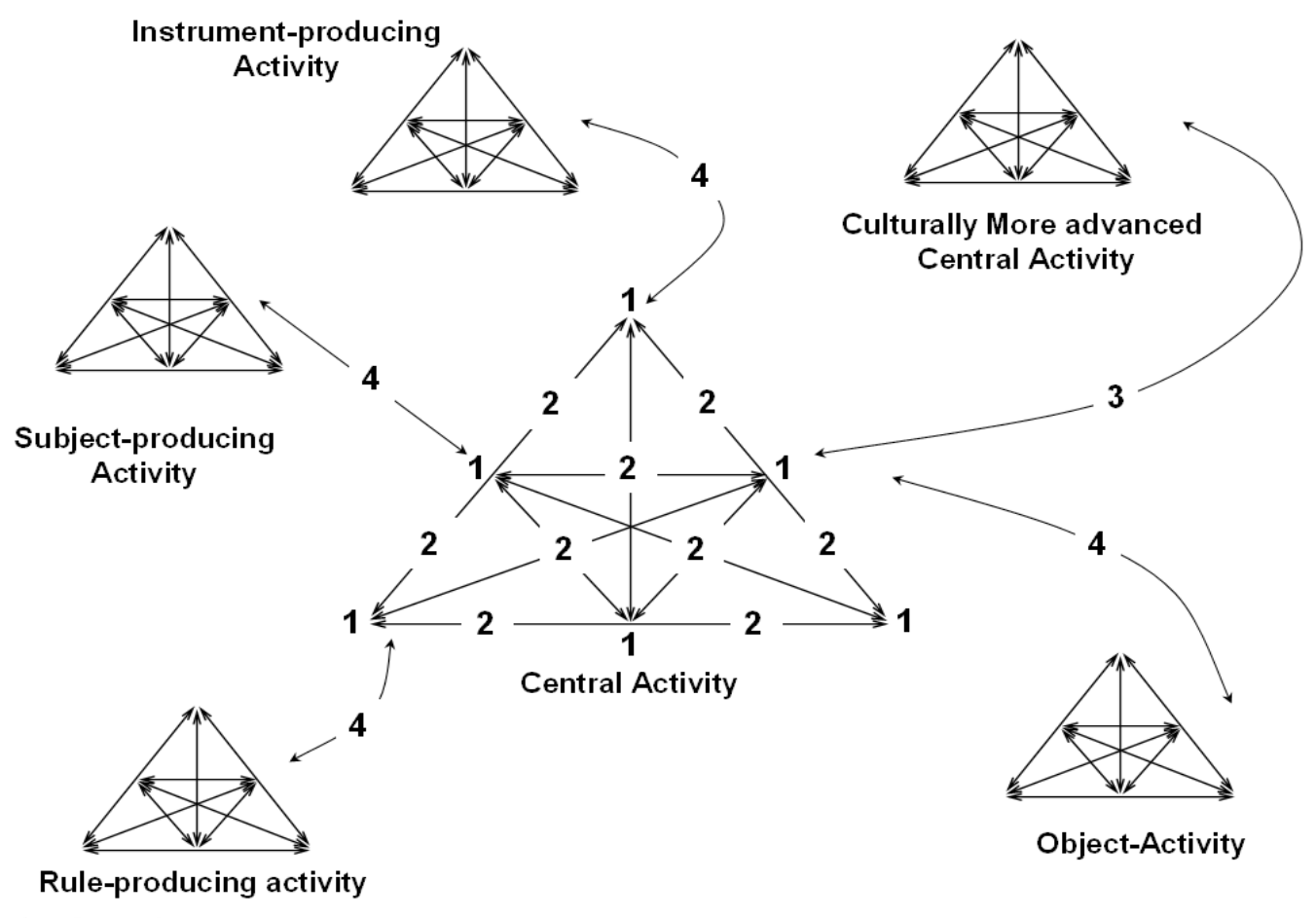

Figure 3. Interactions of surrounding activities and potential contradictions within and between them (Engeström, 1987).

The fourth principle is the role of contradictions in activity systems, the concept central to this case study. Originally introduced by Leont'ev (1981) and further explicated by Ilyenkov (1982), contradictions are understood as potential causes of desirable changes in all activity systems. A contradiction is often "characterized by ambiguity, surprise, interpretation, sense-making, and potential for change" (Engeström, 2001, p. 134). They become visible through disturbances and innovations at the action level of individual participants of activity systems. When contradictions are resolved an activity system undergoes a transformation or sometimes enters a new expansive cycle of growth, the last of the five principles of activity theory proposed by Engeström (2001).

Engeström proposes four levels of contradictions: primary (1), secondary (2), tertiary (3), and quaternary (4) (Figure 3). The primary contradictions arise within the elements/nodes of the activity system: subject, object, instruments, community, rules, and division of labor.

Engeström (1987) argues that in schooling settings with a capitalist socioeconomic formation, the primary contradictions within the nodes of activity acquire the nature of use and exchange value. In his example, text represents the object of learning, which can be studied in exchange for grades or for meaningful use in real life. Instruments oriented towards exchange value require recall and memorization; whereas, instruments that call for meaningful use of knowledge provide means for investigation and real-life problem-solving. Division of labor oriented towards exchange value calls for isolated roles, while division of labor oriented towards use value encourages cooperation. Community oriented towards 
exchange value produces a class of separate individuals, but when it is oriented towards use value, it creates a team of inquiry. Rules oriented towards the exchange value create competition. Rules oriented towards the use value encourage risk-taking. Finally, a student as a subject is either a grade-maker when oriented towards the exchange value of the object or is a sense-maker when oriented towards the use value of his or her object. Thus, an activity where the subject is oriented towards the exchange value of the object leads to alienation because there is no true collaboration in the community node. An activity where the subject is oriented towards the use value of the object leads to inclusiveness and collaboration.

Secondary contradictions occur between the nodes of an activity system, and tertiary and quaternary contradictions occur between different activity systems. Engeström (1987) provides an example of instruments that a doctor uses in his practice. A doctor may be faced with a contradiction of how much to spend on the instruments to maintain his/her cost efficiency (i.e., a contradiction between use value and exchange value of medical instruments). The secondary contradictions (2) are those that emerge between these nodes within an activity system. According to Engeström, traditional instruments used in biomedicine (instruments) may be inadequate for diagnosing the patients with complex illnesses (object).

The tertiary contradictions (3) arise when a culturally more advanced activity within the central activity of interest introduces a more advanced object or motive. This could be illustrated with a clinic administration introducing new methods of diagnoses that run counter to the traditions of some doctors in that clinic.

Finally, the quaternary contradictions (4) exist between the central activity system and the outside activity systems. The latter could be of four types: a) an activity system of object (e.g., diagnosing and treating patients); b) a rule producing activity system (e.g., the clinic administration); c) a subject producing activity system (e.g., medical schools that prepare doctors and nurses); and d) an instrument producing activity system (e.g., a company that provides drugs and other medical instruments).

To date, some thought-provoking research has been done to investigate distance education or technology-enhanced environments through the lens of contradictions. Fåhræus (2004), Basharina (2007), Berge and Fjuk (2006), and Dippe (2006) have analyzed contradictions in activity systems in distance and online environments. Their methodologies vary from analyzing survey results for potential disruptions to working with heavily triangulated data and changing the unit of analysis from action to activity. Some other studies have looked at contradictions caused by instructional technologies in nondistance settings (Barab et al., 2002; Hardman, 2007; Russell \& Schneiderheinze, 2005). Again, the researchers conceptualize contradictions slightly differently from keeping it simple to very complex.

One underlying theme in all these studies is the assumed complexity of reality. Many of them also connect contradictions to transformations in activity systems. As such, this kind of research looks for patterns of growth or failure and identifies disruptions that cause them. Murphy and Rodrigues-Manzanares (2008) offer a concise summary of many of these and other studies in terms of their scope, methodologies, findings, and implications. 
This study approaches contradictions methodologically somewhat differently from many of the studies cited above. First, we go down to the levels of actions to identify specific disturbances and innovations and then map them out to the level of activity systems. Similar zooming-in-and-out approaches have been adopted by Barab et al (2002) and to some degree by Basharina (2007) and Berge and Fjuk (2006). However, this study particularly operationalizes contradictions as consistent occurrences of disturbances and innovations at the action level. We believe this approach is more justified theoretically and affords a more fine-tuned view of interactions between individual actions and their repercussions in the web of activity systems. Another new take of contradictions in this research is the focus on primary contradictions between use and exchange values. This approach allows us to explore how individual participants make philosophical decisions and how they impact central activity systems.

This case study views learners of a distance course as subjects of their own activity systems. Each activity system had its own object, that is motive that provided impetus and direction to the activity. Each subject was mediated by his or her instruments, community of classmates and instructors, division of labor, and rules outlined in the course syllabus. The activity systems of each individual student also interacted with other external activity systems including the Internet provider in the country, students' family and work, the Institute, and the government, thus creating a web of complex contradictions that led to consequences, that is transformations either positive or negative.

To this end, the study addresses the following research questions:

1. What types of contradictions arise at the four levels of the central activity systems of individual learners: primary, secondary, tertiary, and quaternary?

2. What are the consequences of the identified contradictions? 


\section{Methodology}

Research conducted within the activity theoretical framework calls for a research design that would afford an in-depth study of an activity system or a constellation of interacting activity systems. A single activity system belongs to an individual subject, such as a person, or a collective subject, such as a class, school, or society. Movement from the unit of analysis of actions to that of activity is also a critical aspect of activity theoretical methodology (Barab et al., 2002; Engeström, 2001). Given that the main unit of analysis in this study is an activity system with an individual student as a subject, we opted for a case study design. A single case in this design represents a central activity system of one student taking the critical thinking bridge course. There were a total of six student cases.

Lincoln and Guba (1985) characterize this kind of research as naturalistic inquiry that typically employs qualitative methods of investigation. Many studies conducted within the framework of activity theory abide by the principles of naturalistic inquiry (Barab et al, 2002; Lantolf \& Thorne, 2006; Mwanza, 2002; Nardi, 1996a, 1996b).

\section{The Institute}

Two major forces have shaped the current state of the Bahá'i Institute for Higher Education (the Institute): the persecution of the Bahá'í community by the Iranian government and the Bahá'i culture that calls for the pursuit of high quality education and positive change in society. Among the victories of this struggle are the extended academic programs at the Institute, restructuring of courses for distance or blended mode of delivery, affiliated global faculty (AGF) outside Iran, and a new curriculum for academic English delivered at a distance. This clearly makes the Institute infrastructure more independent of the physical facilities, hence less vulnerable to the detrimental activities of the government. Some Institute graduates have been able to continue their education in graduate schools outside Iran. However, because the Institute cannot be formally accredited in this country for political reasons, the potential of this education to exert influence on the lives of the young Baha'is remains embryonic.

A number of other constraints counteract the efforts of the Institute. Among them is a constant threat to the administrative body of the Institute that sometimes results in the imprisonment of key personnel. Internet services in Iran are scrutinized by the government and technically are not reliable. Because the Institute does not have a formal status, many students tend to prioritize other more tangible goals such as work and family over their Institute courses. While the distance model has attracted affiliated global faculty (AGF) teaching a wider range of courses, this shift has also introduced a new challenge. Many students come to the Institute without sufficient English proficiency to handle successfully collegelevel content in English. Extending the curriculum beyond the existing four years to include English preparation so far has not been an option for the Institute. Some students do end up taking degree courses in English without the expected proficiency level in English. 


\section{The Critical Thinking Course}

To address some of the problems with the English proficiency level, the Institute opened a critical thinking course. It served as a bridge course between the academic English language courses and degree courses taught in English from students' major departments. As a bridge course, it pursued two goals: 1) teach critical thinking specific college-level expectations, and 2) improve students' English. The course included eight modules:

- History of Critical Thinking,

- Intellectual Attributes of Critical Thinking,

- Ethical Components of Critical Thinking,

- Faith and Critical Thinking,

- Asking Questions,

- Evaluating Evidence,

- Detecting Fallacies,

- Consensus Building and Critical Thinking.

Students completed several types of assignments throughout the course:

- a draft and final paper based on each reading assignment;

- asynchronous threaded discussions (forums);

- two optional assignments for bonus points, a wiki prewriting activity and a synchronous session (audio- or chat-based) with the instructors.

The course was delivered via Moodle and lasted 15 weeks. Due to poor Internet connectivity in Iran, and sometimes the absence thereof, the reading materials were also available on CDs.

Figure 4 summarizes some of the aspects of the setting in the form of a course taking activity system. Many features of this activity system are the same across all student participants (e.g., certain rules, such as due dates and plagiarism policy, division of labor, and technological instruments, such as Skype, Yahoo Messenger, Moodle, telephone, CDs). However, some others differ across students. Among those unstable features is the student's object. 


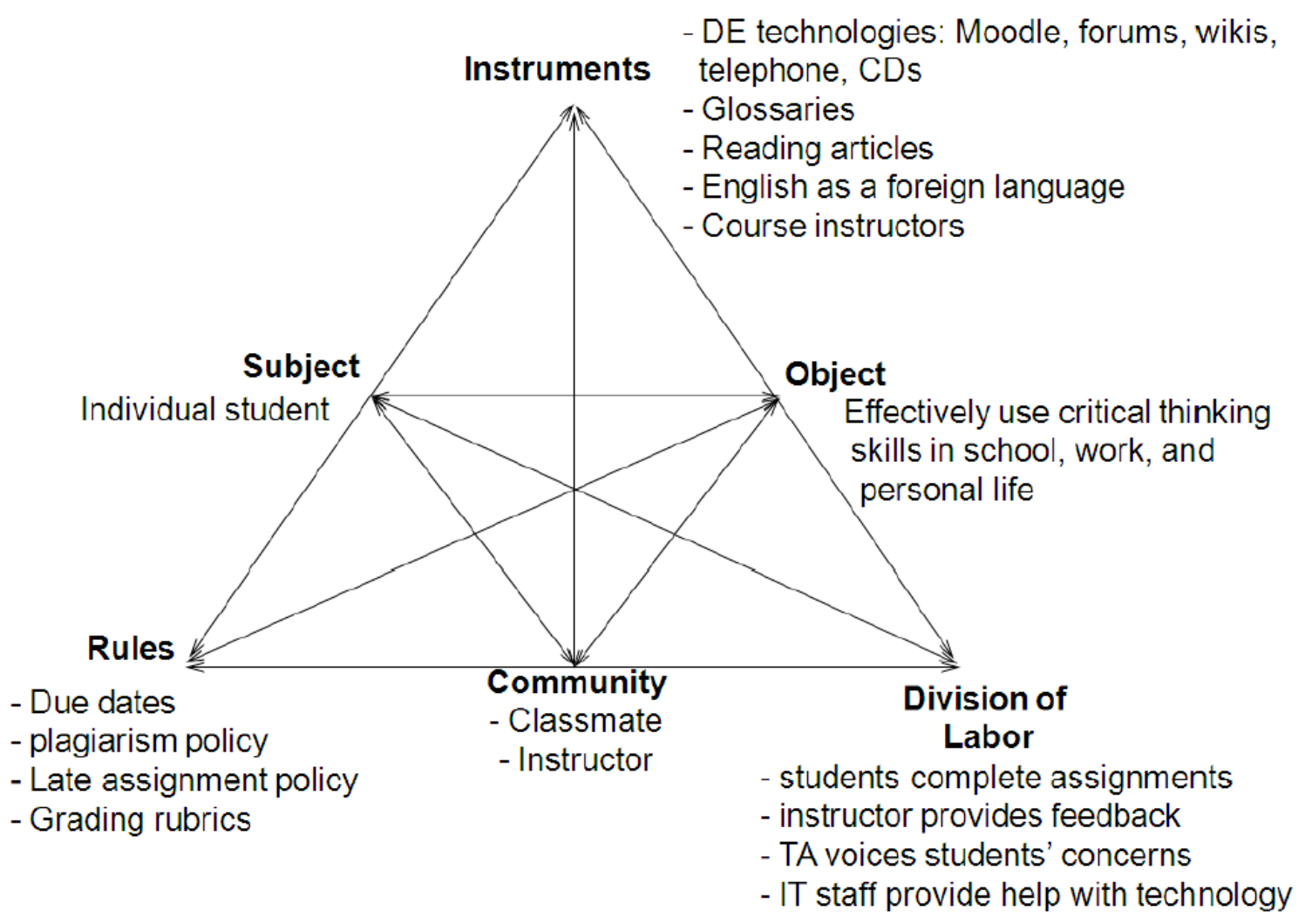

Figure 4. A generic course taking activity system.

\section{Participants}

Out of the total 68 students in the course, we selected six student participants based on a purposive sampling approach. Key criteria for ensuring maximum variation included age, gender, English-proficiency, major, and employment. Among the six students, three were male and three female; age ranged from 18 through $36(M=23)$. Their English proficiency level roughly ranged from low-intermediate to advanced. All except two students majored in different academic programs: management, psychology, pharmacy, computer engineering, and biology. Three were employed and three unemployed.

Of the five instructors involved in this distance course, four taught the selected student participants. None of the instructors spoke Farsi, the students' native language. Two of them had MA degrees and two PhD degrees in areas related to critical thinking and/or English as a second language.

One of the researchers was also a course instructor. The other researcher performed administrative duties and was familiar with the inner workings of the Institute and students' academic routines. By the time data collection started, all six student participants and their instructors had established trustworthy relationships with the researchers. 


\section{Data Collection and Analysis}

To ensure an accurate representation of student activity systems and their dynamics, data had to be collected and analyzed consistently throughout the semester. The following are the datasets collected and analyzed during and after the course:

- student background questionnaire,

- all student assignments submitted to the Moodle course site,

- Moodle-tracked logs to identify students' online presence and behavior,

- interactions between the student and instructor participants,

- monthly semistructured interviews with the student participants,

- an interview with the students' instructors at the end of the semester,

- researcher field-notes.

Most of the data collection and analysis took place concurrently and recursively. Overall, the study procedure can be summarized in three stages (Figure 5). The second stage involved three to four cycles of data collection and analysis procedures: 1) observing the students' online participation, 2) confirming the emerging evidence through interviews with the students, 3) interpreting preliminary contradictions and their consequences (identifying patterns of disturbances and innovations within activity systems), and 4) preparing data for member checking in the subsequent interview. Cycles 1 through 4 proceeded in an iterative manner, each lasting about two weeks. Observation of students' online participation was done through Moodle tracked data. Stage 3 took place when the critical thinking course was over and all the data were collected. 


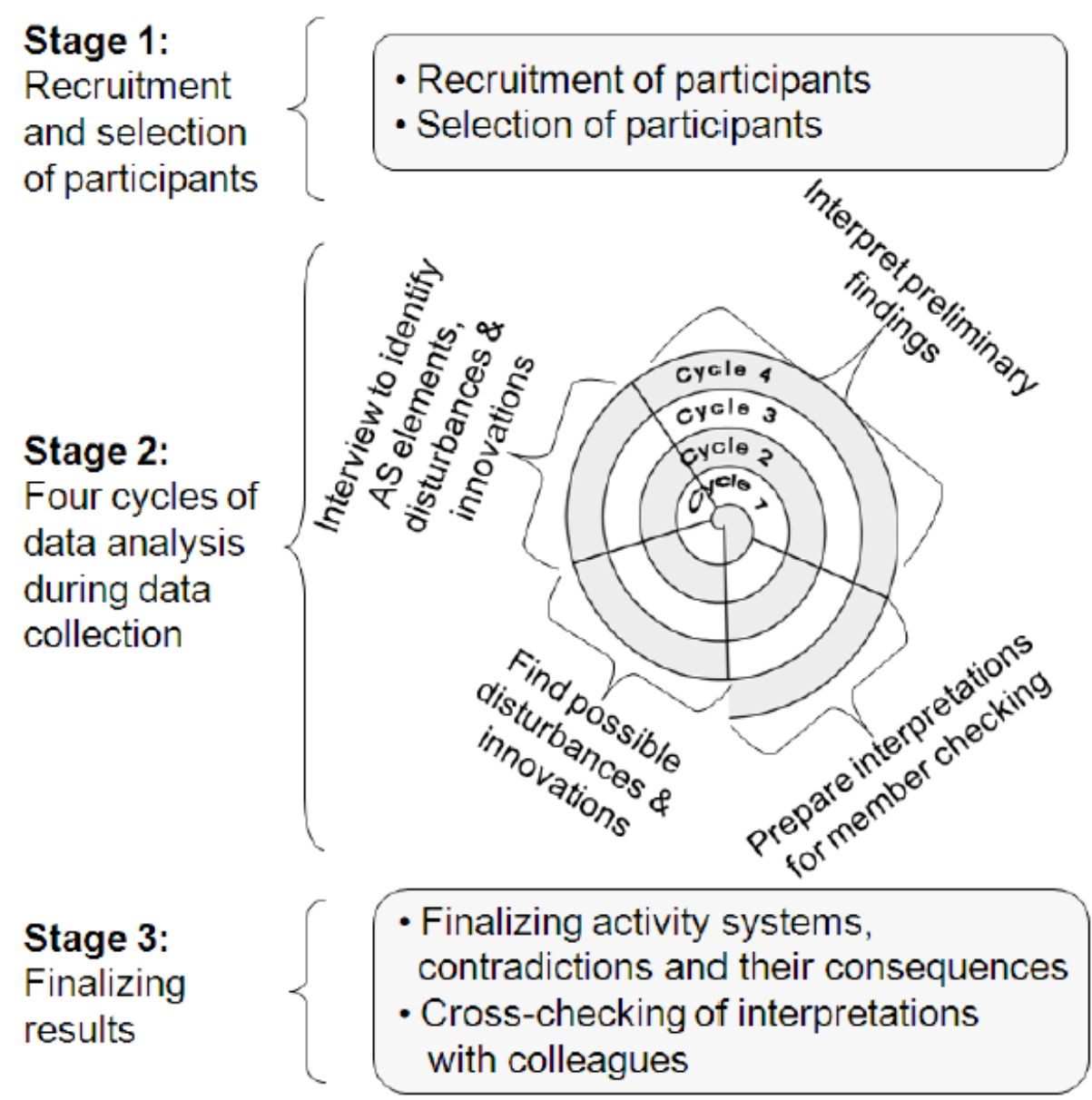

Figure 5. Three stages of data collection and analysis.

All the data were collected and analyzed in the ATLAS.ti software application. Each dataset was read and preliminarily coded as possible evidence for

- disturbances or innovations;

- elements of activity system (instruments, object, division of labor, community, and rules); and

- consequences of contradictions.

Theoretically, disturbances or innovations occur at the action level of activity systems, and if they occur consistently, they lead to underlying contradictions (Engeström, 1999a). The next step was to generate questions for the follow-up interview based on the collected data in ATLAS.ti. Finally, when the activity systems, contradictions, and their consequences were finalized in stage 3 , the interpretations were cross-checked between the researchers. 


\section{Findings}

Given the thick description and extended discussion of the analysis, this article illustrates the analysis of data using one of the six cases only and then draws generalized conclusions based on all six student cases. The names of the participants of the study have been changed to protect their identity.

\section{Azita's Activity Systems}

Azita, 23, was a student majoring in management. She was single, lived with her mother and father, and had a Bahácí religious background. Her sister, who taught English, lived separately, but they saw each other twice or three times a week. While taking an average of 16 credit hours of coursework at the Institute per semester, Azita worked part-time for a computer company where she repaired computers and did related secretarial paperwork.

According to activity theory, actions performed in our daily life are poly-motivated meaning they may belong to multiple activity systems; in other words, they are driven by multiple motives or objects (Leont'ev, 1978). The boundaries between activity systems are hard to demarcate, but methodologically they could be defined by their objects. Within the critical thinking course, all student participants had multiple activity systems.

Azita was engaged in three activity systems that corresponded to the following three objects or motives: 1) learning critical thinking, 2) improving English as a foreign language (EFL), and 3) maintaining a good self-image (Figure 6). 


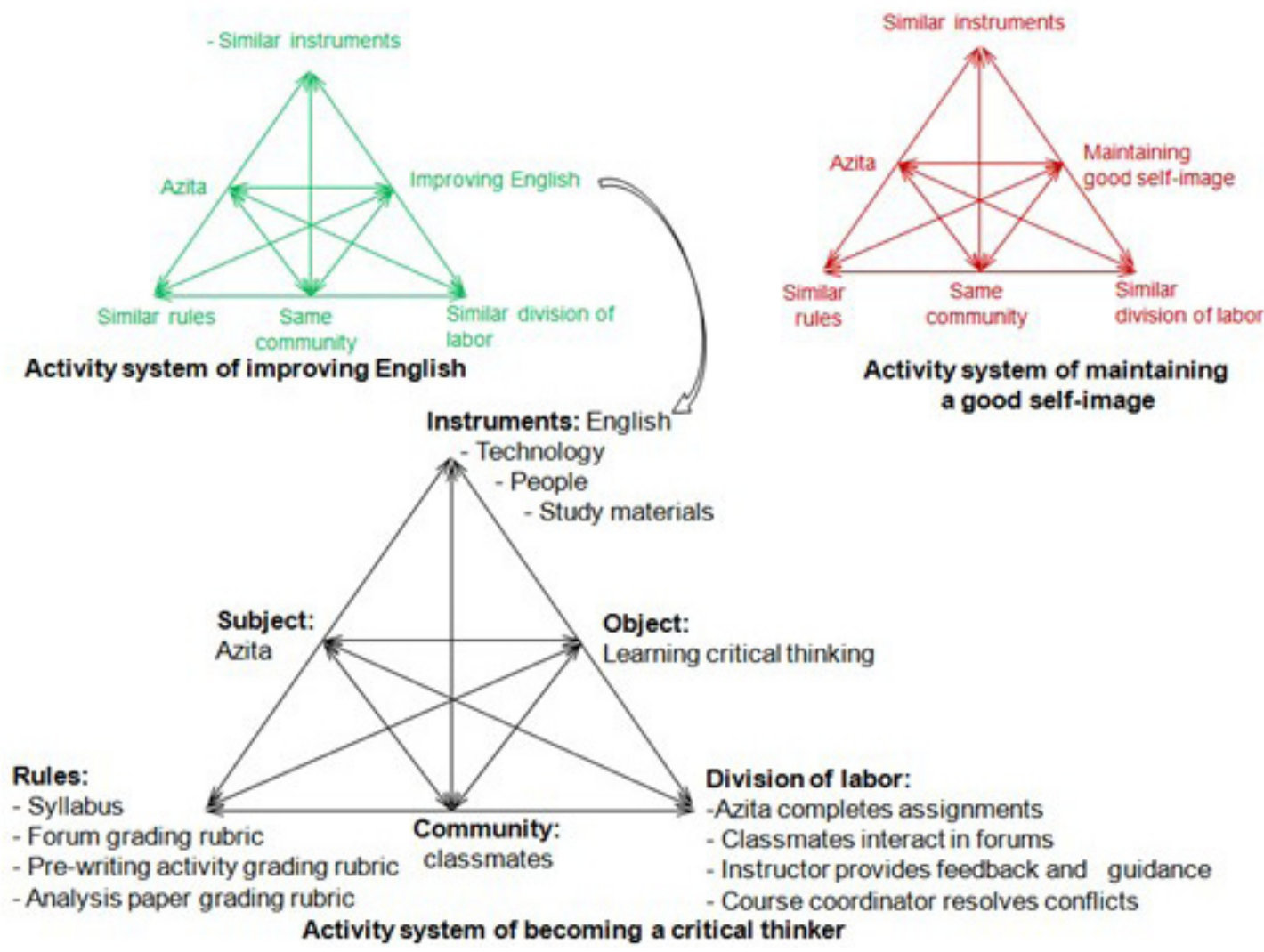

Figure 6. Azita's three activity systems in the critical thinking course.

The activity system of learning critical thinking appears more salient in Figure 6 because the original intent of the course was to teach critical thinking. In this activity system, one of the mediating instruments was English as a foreign language (EFL). This is due to the nature of the course to teach college-level content via English. This is one of the enlightening advantages of activity theory in that it is able to demonstrate that the linguistic medium of instruction in a course like that is a mediating instrument, and as such it begs for improvement if not adequate to fulfill its mediating functions. Such a dual role of certain elements as objects and instruments in two different activities is common (Engeström, 1987).

Other mediating instruments included study materials and assignments. In Azita's group, the teacher occasionally posted PowerPoint slides to facilitate their reading assignments. Assignments were also part of the mediating instruments, and they included the analysis papers for every module, three problem-solution forums, and two optional assignments: 1) prewriting assignments, and 2) conference calls.

Under the technology category, the mediating instruments included the Moodle content management system, the articles in HTML format with hyperlinked glossary items, an ADSL Internet connection, and computer-based dictionaries. Another mediating instrument in Azita's activity system is her English-speaking sister. From the interviews with Azita, it appeared that her sister acted as a help-on-demand resource. 
The rules were established by the course designers through the course syllabus: course goals, objectives, topics, and the calendar. The syllabus stipulated the grading policy and due dates. For every day late, the assignment would lose $10 \%$ of the grade. The grading rubrics were also part of the rules in this course context, and they included the grading rubrics for the problem-solution forums, analysis papers, optional prewriting activities, and optional conference calls.

Finally, the community consisted of Azita's instructor and her classmates. The instructors in this course played a critical mediating role in transforming and shaping the student participants' objects.

Of the three activity systems that Azita engaged in, some maintained stability, while others changed due to contradictions. Figure 7 provides a simplified representation of the historicity of the three activity systems. Activity systems cannot possibly be represented with three activity triangles within the span of a semester because of their inherently dynamic nature. Nevertheless, this diagram gives an idea of what the student participants felt most (a large triangle) and least (a small triangle) motivated about. One can also observe that there is no growth of any of the three activity systems over time. Instead, they tend to shrink. The changing dynamics of the three activity systems and their objects are largely due to their interactions with other activity systems, a conclusion that we can draw when interpreting data based on Engeström's (2001) explication of activity theory. 
Contradictions in a Distance Course for a Marginalized Population at a Middle Eastern University

Madyarov and Tref
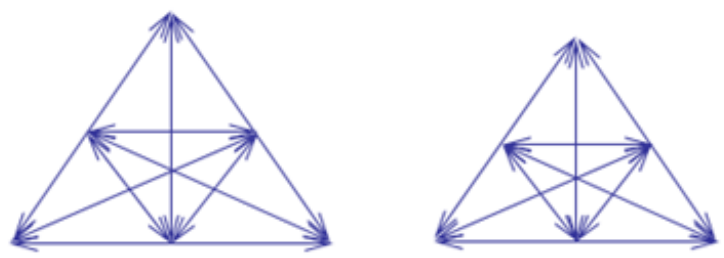

을
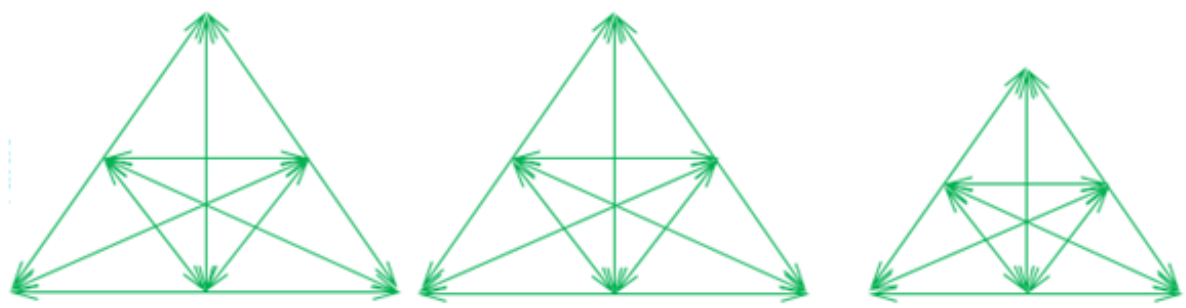

壱
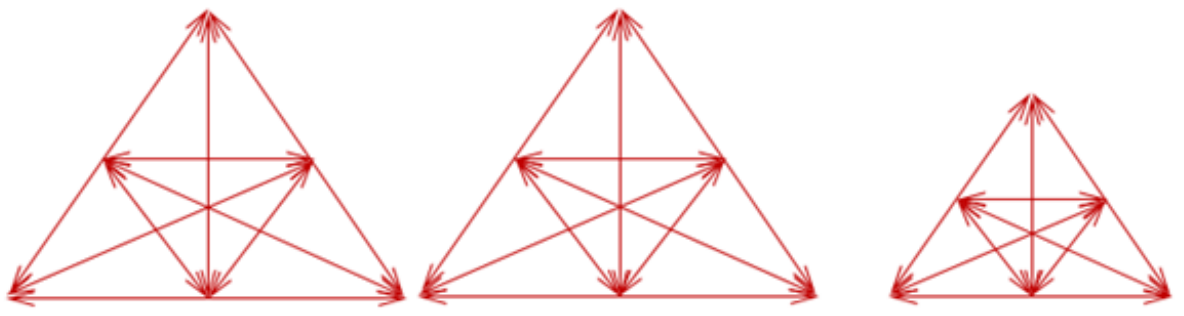

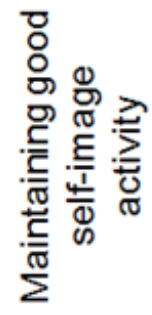

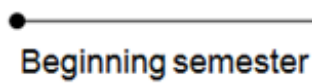

Mid semester

End semester

Figure 7. Illustration of the historicity of Azita's activity systems in the course.

Azita's Primary Contradictions and Consequences

One of the primary contradictions in the node of technological instruments was that between the use and exchange value of the Internet. This instrument is a pure commodity where the relationship between the use and exchange values is obvious. Azita must have made a conscious decision to purchase a high-speed Internet connection, and her decision saved her from potential secondary contradictions between the Internet-based technologees and her course-related objects.

Another primary contradiction that emerged in the data belongs to the node of community, in particular in relation to Azita's classmates. Some of Azita's initial forum posts made an impression that she was initially genuinely interested in communicating with her classmates,

Hi Dears, As you know we are going to write some analysis papers about some specific articles. [...] Let's help each other and share ideas to do our best. I just wanted to start the discussion of pre-writing activity. I am waiting for your cooperation.

Vol 13 | No 2

Research Articles

April 2012

92 
This forum post was met with a wall of silence for the rest of the semester. Her intention was to use her classmates' ideas to mediate her own understanding of the articles and assignments. This kind of relationship in the online community, where members share ideas that they have and receive in return helpful ideas from other members, is obviously highly desirable. However, having experienced a lack of interest from her classmates, she retreated and interacted with them minimally for the sake of the grade. In other words, this primary contradiction was primarily oriented towards the exchange value of the community.

\section{Azita's Secondary Contradictions and Consequences}

Most contradictions that transpired in this study were at the secondary level, which is also consistent with theoretical literature (Engeström, 1987, 1999, 2001).

One secondary contradiction in Azita's activity systems occurred between Azita's instrument and her object of critical thinking. EFL as an instrument prevented Azita from a smooth transformation of the critical thinking object. This contradiction was manifested through the instructor-initiated disturbances in the feedback on draft analysis papers. Some of this feedback was caused by the instructor's genuine confusion over what Azita wanted to say. Azita herself also initiated some disturbances, such as this explicit statement in her paper: "I do not understand what he [the author] means." The instructor would then follow up on such comments in her feedback. Other positive consequences of this contradiction included repeated use of dictionaries, hyperlinked glossary words, her sister's help, and, less rarely, referring to a grammar book. The most frequent way to resolve those disturbances was rereading the articles many times to gain a better understanding. When unresolved, this contradiction potentially could have impeded Azita's activity systems, which we do not have data to support.

Another secondary contradiction occurred between the rule (due dates) and Azita's objects of learning critical thinking and EFL. There were several instances of late paper submissions and two of them were caused by Azita's illness. According to the course syllabus (rule), Azita would lose 10\% for every day late. In spite of this, she did not because the instructor thought it unfair to drop points for lateness because this would wrongly imply a poor quality of the paper. Thus, this particular contradiction did not lead to any consequences in Azita's activity systems.

\section{Azita's Quaternary Contradictions and Consequences}

The data show that there were two quaternary contradictions in Azita's activity systems. The first one was a contradiction between Azita's activity systems in the critical thinking course and the activity system of the Iranian government directed against the Bahácí community in Iran. In Spring 2008, the government shut down many Institute facilities in Tehran making it impossible for many classes to meet face-to-face. Many such courses were urgently forced to go online well underprepared the same semester when this critical thinking course was investigated. 
This disturbance in Azita's other online courses hastily launched that semester affected her experience in the critical thinking course. In the last interview she stated, "they [students] can't learn anything. I think it has ... bad effect on students. ...Because the Institute became online, many students don't like this university. ... I'm not learning much from online courses."

Another quaternary contradiction emerged between Azita's work at a computer company and potentially all three of her activities in the critical thinking course. The disturbances that underlay this contradiction included late submissions and poor quality of papers and forum posts. This contradiction created a secondary contradiction in Azita's course activities between the due dates (rules) and two of her course-related objects: critical thinking and EFL.

\section{Summary of the Findings}

Now that we have illustrated the data analysis and interpretation within this methodological framework, let us turn to the synthesized findings of all six student cases.

\section{Student Objects}

One general conclusion one can draw from the findings of the six cases is that five student participants had multiple activity systems in the critical thinking course. This goes back to Leont'ev's (1978) argument that actions are often poly-motivated and rarely driven by one motive alone. One of the students had only one activity system, and that is perhaps why he dropped out of the course halfway through the semester. The most obvious pattern is that most students had the objects of improving English and critical thinking. There were three participants who had either of these two objects. Two other participants had a more general object of intellectual self-development that subsumed either EFL or critical thinking learning. Clearly, a course environment with all its mediating elements fosters the emergence of certain types of objects/motives in the students.

\section{Contradictions and Consequences}

The construct of primary contradictions as a duality between use and exchange value in academic-oriented activity systems (e.g., improving English, learning critical thinking) generated some enlightening interpretations. As Engeström (1987) suggests, exchange value orientation leads to student alienation and lack of genuine learning motives in their activity systems, while use value orientation produces self-motivated, collaborative, and critical learners. Most participants shifted from being use value-oriented to exchange value-oriented. Sadly, the course overall was not conducive to orienting the students towards use value. Many reasons for this unfavorable transformation are traced to the role of the rules in the activity systems and the exchange value orientation of individual classmates.

Another interesting finding is that when a participant had an exchange value orientation to the object of learning (i.e., for the sake of the grade), such orientation would spread to the community and rules of the activity system. Simply put, a grade orientation towards 
learning promoted individualistic learners who bend to the rules, such as a grading policy, and become regulated by them. The data provided evidence for three nodes of the activity system: 1) community, 2) rules, and 3) instruments. The latter did not seem to be affected by the orientation in the object possibly because these instruments were pure commodities, such as the Internet and the content management system.

This study confirms Engeström's (1987) argument in that secondary contradictions are the engine of development. All primary and quaternary contradictions inevitably led to secondary contradictions. This course produced a number of consistent secondary contradictions. First and foremost is the contradiction between the insufficient English proficiency of the students and their objects. All six participants had this contradiction, and it resulted in a number of anticipated and innovative transformations, which ultimately engaged students more actively in the use of English.

The next most typical contradiction was between due dates and students' objects. In most cases, this contradiction was resolved by the instructors who adjusted the rule and did not penalize the students for late submissions. However, because this secondary contradiction was primarily caused by quaternary contradictions (e.g., work, family, and government activity against Baha'is in Iran) that could not be negotiated and resolved, their consequences were drastic. These consequences always caused considerable weakening of the object, which manifested itself in the participants' frustration and diminished quality of work. It also resulted in the shift of the orientation from use to exchange value

Three participants had a secondary contradiction between a poor Internet connection and their objects. More often than not this contradiction was caused by the quaternary contradictions coming from the activity system of the local Internet provider. Sometimes it was combined with the primary contradiction between use and exchange value of the Internet connection. This contradiction was resolved by a reduced use of the Internet which in turn negatively affected the transformation of the participants' objects. A few students experienced contradictions with distance technologies as instruments. Asynchronous means of communication such as forums and email were not appealing because of the missing immediacy of responses. Synchronous means of communication, such as Skype, Yahoo! Messenger, or the phone bridge, were not satisfactory because of the poor Internet connection and inflexibility with scheduling the calls. The data showed that this contradiction did not lead to any positive transformations, but instead led to reduced engagement in the course assignments and students' frustration.

\section{Discussion and Conclusion}

Activity theory as a qualitative naturalistic method of inquiry offers some insights that could otherwise have been left unnoticed.

First, at the surface level, five student participants successfully completed the critical thinking course. However, if we apply the constructs of activity motive/object, use and exchange value orientation, and activity systems, the reality emerges in a different light. The students 
who originally were genuinely interested in learning the content, by the end of the course worked only towards their grades. The only student participant who failed this and many other courses that semester did so because he remained use value oriented and naturally refused to work in exchange for a grade when external circumstances (i.e., his work) prevented him from doing so.

From this perspective, the course was not a success, and we wonder if this may be the case with many other distance courses at the Institute where time and space separate the instructors from the students and create an illusion of success reflected in conventional course grades.

Second, the construct of contradictions allowed an in-depth and meaningful analysis of a complex web of relationships starting from the level of student motives to external forces beyond the Institute. At present, the Institute seems to be overburdened with the pressures caused by the government and poor Internet services. Some contradictions lead to successful transformations and take the activity systems of the Institute to new cycles of growth. Yet many others seem to have a detrimental effect on the activity systems of the Institute as well as individual students and instructors. A major cause of this disruption at this point seems to be the forced restructuring of courses for the online mode of delivery. We see several possible scenarios where the Institute could break this contradiction and start a new cycle of growth. The Institute graduates are already accepted in some well-recognized accredited universities outside of Iran. However, if the Institute could find a system to validate their students' degrees such that they become recognized at the international level, it would enable the graduates not only to have more opportunities for work but also to continue in their academic careers more easily. This could give a more tangible motive, that is a use value orientation to students', faculty's, and administration's actions. Two other hypothetical resolutions could come from outside of the Institute: a dramatic change in the current governmental affairs of the country or a dramatic change in current technologies that could solve the many connection disturbances in Iran.

One final comment specific to the theoretical constructs and this particular case study concerns the nature of activity systems. Prior to starting the case study, we expected to be analyzing students' course taking activity systems. What transpired from the data is that none of the students had a course taking activity per se. Instead, the course acted as a favorable environment to sustain students' own activities. In Azita's case, those were improving English, learning critical thinking, and maintaining a good self-image. Theoretically, it makes sense. Boundaries between activity systems are defined by students' objects or motives. Being motivated by an object of taking a course does not quite make sense. Hence, we propose a concept of an activity shell to denote such a ready-made, prepackaged environment that includes all the elements of an activity system except for the subject and object. Most courses in modern school-going often represent such shells in that they have a predesigned structure, where students bring in their existing objects, develop new ones, or simply perform a number of isolated actions not oriented towards any object, much like Engeström (1987) suggests. Forcing students to conform to the structure of an activity system shell is somewhat opposite to the organic formation of human activity in that it is not constructed 
by the subjects of the activity.

If schools and individual courses are activity shells where students get busy transforming their own objects, educators and school administrators may need to reflect on how to match those mediating elements in the activity systems (i.e., instruments, division of labor, community, and rules) to better transform the objects that their students bring to school.

This theoretically conceptualized insight has in fact found its manifestation in many distance courses and schools that have adopted more of an open education approach to their curriculum, content, and technology. The Institute in Iran has taken steps towards adopting this philosophy by opening its doors to all applicants and by removing many of the gatekeepers such as standardized tests, entrance exams, previous experience, and the like. It seems to us that the Institute could resolve many of the deadly contradictions in its activity systems if it moved more in the direction of open philosophy in terms of content, knowledge, and technology, as current literature suggests (e.g., Brown \& Adler, 2008; Caswell, Henson, Jensen, \& Wiley, 2008; Iiyoshi \& Kumar, 2008). One particular example of such emerging developments is OpenClass, a learning management system produced by Pearson and Google, that aims to bring the open philosophy to blended and distance education. A distance school with an activity system shell that adheres to open philosophy may be more successful in mediating their students' objects towards the use value while at the same time withstanding the oppressive forces from the outside. 


\section{References}

Barab, S. A., Barnett, M., Yamagata-Lynch, L., Squire, K., \& Keating, T. (2002). Using activity theory to understand the systemic tensions characterizing a technology-rich introductory astronomy course. Mind, Culture, and Activity, 9(2), 76-107.

Basharina, O. K. (2007). An activity theory perspective on student-reported contradictions in international telecollaboration. Language Learning \& Technology, 11(2), 82103.

Berge, O., \& Fjuk, A. (2006). Understanding the roles of online meetings in a net-based course. Journal of Computer Assisted Learning, 22(1), 13-23.

Brown, J. S., \& Adler, R.P. (2008). Minds on fire: Open education, the long tail, and learning 2.o. EDUCAUSE Review, 4O(1), 16-32. Retrieved from www.educause.edu

Caswell, T., Henson, S., Jensen, M., \& Wiley, D. (2008). Open educational resources: Enabling universal education. International Review of Research in Open and Distance Learning, 9(1), 1-11. Retrieved from http://www.irrodl.org/index.php/irrodl/article/viewArticle/469.

Dippe, G. (2006). The missing teacher: Contradictions and conflicts in the experience of online learners. Retrieved from http://hal.inria.fr/docs/oo/19/03/03/PDF/Gunther-Dippe-2006.pdf.

Engeström, Y. (1987). Learning by expanding: An activity-theoretical approach to developmental research. Retrieved from http://communication.ucsd.edu/MCA/Paper/ Engeström/expanding/toc.htm

Engeström, Y. (1999a). Activity theory and individual and social transformation. In Y. Engeström, R. Miettinen, \& R. L. Punamäki (Eds.), Perspectives on activity theory, (pp. 19-38). New York: Cambridge University Press.

Engeström, Y. (1999b). Expansive visibilization of work: An activity-theoretical perspective. Computer Supported Cooperative Work, 8, 63-93.

Engeström, Y. (2001). Expansive learning at work: Toward an activity-theoretical reconceptualization. Journal of Education and Work, 14(1), 133-156.

Fåhræus, E. R. (2004). Distance education students moving towards collaborative learning - A field study of Australian distance education students and systems. Educational Technology \& Society, 7(2), 129-140.

Hardman, J. (2007). Making sense of the meaning maker: Tracking the object of activity in a computer-based mathematics lesson using activity theory. International Journal 
of Education and Development using Information and Communication Technology, 3(4), 110-130.

Bahá'í Institute for Higher Education. (2011). History and overview. Retrieved from www. bihe.org.

Iiyoshi, T., \& Kumar, M. S. V. (Eds). (2008). Opening up education: The collective advancement of education through open technology, open content, and open knowledge. Massachusetts Institute of Technology.

Ilyenkov, E. V. (1982). Dialectics of the abstract and the concrete in Marx's Capital. Retrieved from www.marxists.org/archive/ilyenkov/works/abstract/index.htm.

Lantolf, J. P., \& Thorne, S. L. (2006). Sociocultural theory and the genesis of second language development. Oxford: Oxford University Press.

Leont'ev, A. N. (1975). Deyatelnost. Soznanie. Lichnost. [Activity, Consciousness, Personality]. Moscow: Politizdtat.

Leont'ev, A. N. (1978). Activity, consciousness, and personality. Retrieved from the Marxist Internet Archive Web site: http://marxists.anu.edu.au/archive/leontev/ works/1978/index.htm.

Leont'ev, A. N. (1981). Problems of the development of the mind. Moscow: Progress Publishers.

Leont'ev, A. N. (1989). The problem of activity in the history of Soviet psychology. Soviet Psychology, 27(1), 22-39.

Lincoln, Y. S., \& Guba, E. G. (1985). Naturalistic inquiry. Newbury Park, CA: SAGE. Publications, Inc.

Murphy, E., \& Rodrigues-Manzanares, M. A. (2008). Using activity theory and its principle of contradictions to guide research in educational technology. Australasian Journal of Educational Technology, 24(4), 442-457.

Mwanza, D. (2002). Towards an activity-oriented design method for HCI research and practice (Doctoral dissertation). Retrieved from The Open University, United Kingdom: http://iet.open.ac.uk/pp/d.mwanza/Phd.htm.

Nardi, B. A. (Ed.). (1996a). Context and consciousness activity theory and human-computer interaction. London, England: MIT Press.

Nardi, B. A. (1996b). Studying context: A comparison of activity theory, situated action models, and distributed cognition. In B. A. Nardi (Ed.), Context and consciousness: Activity theory and human-computer interaction (pp. 69-102). Massachusetts: The MIT Press. 
Russell, D. L., \& Schneiderheinze, A. (2005). Understanding innovation in education using activity theory. Educational Technology \& Society, 8(1), 38-53.

Vygotsky, L. S. (1982). Problemy obshei psikhologii. [Problems of general psychology]. Moscow: Pedagogika.

\section{Athabasca University $\mathbf{I}$}

(c) (P) 